\title{
La solidaridad chilena con la primera guerra de independencia de Cuba: sus tensiones y contradicciones
}

\author{
Ricardo López Muñoz ${ }^{1}$ \\ Recibido: 15 de mayo de 2015 - Aceptado: 10 de junio de 2015
}

\begin{abstract}
Resumen
La solidaridad que Chile manifestó con la primera guerra de independencia de Cuba (1868-1878) estuvo marcada por el declinar de un americanismo que había sido preeminente en la sociedad en el contexto de las intervenciones europeas sobre Hispanoamérica a inicios de la segunda mitad del siglo XIX y, especialmente, ante la guerra de Chile con España en 1865. El artículo expone y analiza las características contradictorias de esta solidaridad, que, por una parte, expresó la deriva cultural de la mayoría de las élites chilenas hacia una visión de su país en donde sólo importaban sus procesos internos y su diferenciación con el resto del continente y que, por otra parte, evidenció la existencia de un americanismo ciudadano, solidario con la causa de Cuba. Ambas perspectivas convivieron con dificultad, negociando su interacción, hasta que finalmente primó la primera, pasando el americanismo al olvido entre la comunidad patricia chilena.
\end{abstract}

Palabras clave: americanismo, solidaridad chilena, Cuba, ciudadanía.

\section{Chilean solidarity in the Cuba's first war of independence: tensions and contradictions}

\begin{abstract}
Chile expressed solidarity with the first war of independence in Cuba (18681878), which was marked by the decline of an Americanism that had been prominent in society in the context of European interventions on Latin America at the beginning of the second half of the Nineteenth Century and especially before the war between Chile and Spain in 1865. The article describes and analyzes the contradictory characteristics of this solidarity, which, on the one
\end{abstract}

Chileno. Licenciado en Historia por la Universidad de La Habana, Cuba, y Doctor en Estudios Latinoamericanos por la Universidad de Chile. Este trabajo es parte de la investigación doctoral titulada "El Americanismo en Chile ante la expansión política y militar europea sobre Hispanoamérica (1861-1871)". Profesor en la Facultad de Filosofía y Humanidades de la Universidad Alberto Hurtado, Chile. E-Mail: rilomu@outlook.com 
hand, expressed the cultural drift of most Chilean elites towards a vision of their country which only focused on its internal processes and differentiation with the rest of the Continent and that, on the other hand, revealed the existence of a citizen Americanism, in solidarity with the Cuba's cause. Both perspectives coexisted with difficulty negotiating their interaction until the first prevailed, leading to the oblivion of Americanism among Chilean patrician community.

Keywords: Americanism, Chilean solidarity, Cuba, citizenship.

\title{
A solidariedade chilena com a primeira guerra da independência de Cuba: suas tensões e contradições
}

\begin{abstract}
Resumo
A solidariedade que Chile expressou com a primeira guerra de independência de Cuba (1868-1878) foram marcadas pela queda de um americanismo que tinha sido proeminente na sociedade no contexto das intervenções europeias sobre a América Latina no início da segunda metade do século XIX e, especialmente, antes da guerra entre o Chile com Espanha em 1865. 0 artigo expõe e analisa as características contraditórias desta solidariedade, que, por um lado, expressou a deriva cultural da maioria das elites chilenas em direção a uma visão de seu país onde só se preocupam dos seus processos internos e sua diferenciação com o resto do continente e que, além disso, revelou a existência de um americanismo cidadão, solidário com a causa de Cuba. Ambas perspectivas coexistiram com dificuldade, negociando sua interação até que finalmente prevaleceu a primeira, passando ao esquecimento 0 americanismo entre a comunidade patricia chilena.
\end{abstract}

Palavras-chave: americanismo, solidariedade chilena, Cuba, cidadania.

La historia de la relación de Chile con el independentismo cubano, y en particular con su primera guerra de independencia, acaecida entre 1868 y $1878^{2}$, no ha sido objeto de análisis por los historiadores. Puntuales artículos divulgativos aluden someramente al apoyo que Chile brindó al independentismo de la isla por intermedio de Benjamín Vicuña Mackenna, cuando -en el contexto de la guerra con España de 1865- fue enviado como Agente Confidencial del gobierno a los Estados Unidos (Orrego, 1951; Ba-

2 En el siglo XIX Cuba sostuvo dos guerras de independencia. A consecuencia de las rivalidades entre los independentistas más el desgaste de una década de combates, la primera culminó con la firma de un pacto con las autoridades españolas, el 10 de febrero de 1878, con el que se dio término a la guerra, sin que alcanzara sus objetivos. La segunda aconteció entre 1895 y 1898, y fue interrumpida por la intervención militar de los Estados Unidos sobre la isla. Para conocer las características y diferencias de ambas guerras recomendamos consultar (Torres-Cuevas y Loyola, 2002, y Zanetti, 2013). 
rrios, 2007). Sin embargo, estas menciones se orientan en lo fundamental a destacar el americanismo y la personalidad del ilustre liberal. Más allá de estas reseñas -que refieren a un proceso previo a la guerra que se inició en Cuba en 1868-, la relación entre ambos países permanece ignorada. Nos proponemos en el presente artículo develar la relación que sostuvo Chile con el independentismo cubano del período 1868-1878, como un proceso que reflejó la transición de un americanismo solidario preeminente dentro de la cultura política chilena en el contexto de las intervenciones europeas sobre Hispanoamérica de inicios de la segunda mitad del siglo XIX, hacia una perspectiva política cuyo centro sería el propio país, y sus dinámicas internas, lo cual involucró una renuncia explícita al americanismo. Los actores chilenos de esta transición fueron los que en distintas circunstancias se vincularon con la causa cubana, evidenciando en sus conductas las tensiones y contradicciones de una solidaridad intermitente y en gradual declive, conforme podía implicar compromisos innecesarios para un país que poco a poco se centraba en sí mismo.

El primer contacto entre ambos países estuvo precedido por la anexión de Santo Domingo por España en 1861; las intervenciones de Inglaterra, Francia y España sobre México ese mismo año; la ocupación de ese país por parte de Francia en 1862; y la ocupación en 1864 de las islas peruanas de Chincha por una escuadra de guerra española. Estas intervenciones determinaron que buena parte de la sociedad chilena percibiera amenazadas la independencia y el republicanismo en Hispanoamérica. Desde esta perspectiva, parte de las élites y de los sectores medios plebeyos urbanos se organizaron para respaldar a los agredidos y promover la integración del continente para su defensa (López, 2011). Lo hicieron a través de asociaciones ${ }^{3}$, mítines de apoyo, colectas, y ofrecimientos de voluntarios para combatir a los agresores en los países intervenidos. Por otra parte, particularmente ante la ocupación de las islas Chincha ${ }^{4}$, en el país se manifestó una fuerte simpatía con el Perú y de rechazo a España. Diversas y crecientes expresiones de hostilidad hacia la escuadra, la representación diplomática española, y sus súbditos residentes, tensionaron rápidamente las relaciones entre Chile y el país ibérico, las que llegaron a su clímax cuando el 18 de septiembre de 1865 el jefe de la escuadra española, el almirante José Manuel Pareja, presentó un ultimátum al gobierno. España exigía de Chile disculpas formales por las ofensas inferidas a la corona y a sus súbditos en el contexto del conflicto hispano-peruano y un saludo de 21 cañonazos a su bandera. De no ser así, quedarían rotas las relaciones entre

3 Fueron sobre todo las élites las que se organizaron en sociedades. Varias de ellas tomaron el nombre de Sociedad Unión Americana. Las más importantes fueron las de Santiago, Valparaíso, La Serena y San Felipe.

4 Para conocer los antecedentes, circunstancias y consecuencias de la ocupación de las islas peruanas por España ver a Basadre, 1949: I, 467-516. 
ambos países, la escuadra procedería a bloquear los puertos chilenos, y exigiría una indemnización por los gastos generados por el bloqueo. El 23 de septiembre, con el acuerdo del Congreso en pleno, Chile declaró la guerra a España. Al día siguiente se inició el bloqueo de sus puertos.

A partir de ese momento el gobierno chileno desplegó una estrategia orientada a hacer del conflicto provocado por España una guerra americana. En un "Contra-manifiesto del Ministro de Relaciones Exteriores de Chile sobre la presente guerra entre la República y España", públicamente proclamó que el país emprendía la contienda "con el propósito irrevocable de no terminarla mientras no reciba del gobierno de España la condigna reparación de las ofensas i perjuicios que le ha inferido una agresión indisculpable, i sólidas garantías que pongan para siempre a salvo de futuros e injustos ataques (...) la independencia i reposo de las Repúblicas americanas.", y agregaba, "No es una estéril satisfacción de amor propio el resultado que la República vincula a su triunfo en la actual contienda. Cifra en él la suerte futura de las nacionalidades americanas de origen español, así de las que hoi son libres o independientes, como de las que aún sobre llevan a disgusto, un odioso yugo" (El Ferrocarril, 1865). En otras palabras, Chile se proponía hacer la guerra en nombre y en defensa de América, y por la independencia de Cuba y Puerto Rico. Con este último objetivo el gobierno nombró a Benjamín Vicuña Mackenna como su Agente Confidencial en los Estados Unidos. Sus instrucciones le indicaban al respecto:

"Según los informes que se nos han proporcionado, hai en Estados Unidos numerosos refugiados de Cuba i Puerto Rico, que no cesan de meditar i acariciar proyectos de emancipación e independencia de aquellas islas. Parece que tienen acumulados con tal objeto fondos considerables, i que han formado asociaciones numerosas. Tratará Ud. de entrar en relación con esas asociaciones para ofrecerles el apoyo de nuestros corsarios de las Antillas y concurrir a sus designios por los demás medios que estén al alcance de Ud." (Vicuña, 1867: I, 12-14) ${ }^{5}$.

Vicuña partió a cumplir su misión a fines de octubre. Dejó su país permeado de un americanismo que en el contexto de la guerra con España se había transformado en el principal soporte discursivo del gobierno, las élites y parte de la sociedad plebeya para enfrentar el conflicto. Desde este americanismo intentaría apoyar a los antillanos, iniciando así, especialmente con Cuba, una relación de imprevisibles consecuencias.

Similares instrucciones recibió Manuel Antonio Matta, enviado como Encargado de Negocios ante los gobiernos de Colombia y Venezuela. Empero, Matta no encontraría en su misión a antillanos con los cuales establecer contactos. (Matta, 1872: 17-19). 


\section{El primer encuentro}

Casi recién llegado a Nueva York, Vicuña estableció contacto con la Sociedad republicana de Cuba y Puerto Rico y con sus principales representantes, el cubano Juan Manuel Macías y el puertorriqueño José Francisco Basora. Luego de las primeras conversaciones, el 9 de enero de 1866, Macías, a nombre de la Sociedad, le solicitó a Vicuña que le formalizara la propuesta de su gobierno. Al día siguiente, el Agente Confidencial le respondió por escrito, haciendo precisiones respecto a las ofertas de Chile: el país estaba dispuesto "a prestar a aquellas posesiones todo el ausilio moral i material de que pueda disponer, cuando por actos positivos manifiesten sus habitantes el deseo de emanciparse". Sin embargo, también le manifestaba al cubano su preocupación por "la calma al parecer profunda" que percibía en ambos territorios, por lo que le solicitaba presentarle "un plan de las operaciones en que se propone provocar la insurrección de aquellos países, los recursos materiales con que cuenta en el esterior, la cooperación efectiva que encontraría entre los habitantes de aquellas islas", y todo lo que pudiera contribuir al conocimiento del estado insurreccional de Cuba y Puerto Rico (Vicuña, 1867: II, 140).

A pesar de las aprensiones que Vicuña le expresaba a Macías, su voluntad de colaborar con la independencia de las Antillas hispanas en nombre de su gobierno era sincera. De hecho, conforme al espíritu de sus instrucciones, ya había fundado el periódico La voz de la América, que tenía como subtítulo "Órgano político de las repúblicas hispano-americanas y de las Antillas españolas". El "más importante propósito a que iba a servir (...) era el exitar el justo descontento de los habitantes de Cuba i Puerto Rico, de cuya emancipación se decía abiertamente órgano,..." (Vicuña, 1867: I, 299). Junto con el escrito, le hacía entrega a Macías de trescientos ejemplares del periódico para que fueran remitidos a ambas islas, y le solicitaba la colaboración de los independentistas para que escribiesen en sus páginas. Sin embargo, sus planteamientos no fueron bien recibidos en la Sociedad. Cubanos y puertorriqueños se preguntaron cuáles eran realmente las intenciones de Chile al condicionar su ayuda a "actos positivos". Quien mejor interpretó las posibles lecturas del ofrecimiento fue Basora. Lo hizo en una carta dirigida al agente el 19 de enero. En ella, además de manifestarle al chileno su idea de que no era aún el momento de emprender una insurrección exitosa en Cuba o en Puerto Rico, cuestionaba los ofrecimientos condicionados de apoyo:

$6 \quad$ El objetivo de la Sociedad era: "poner en ejercicio los medios que estén a su alcance para separar a Cuba y Puerto Rico de la dominación española y adquirir una patria libre e independiente" Al respecto ver Roa, 1970: 16-19. 
"Este tiempo que nos falta podría suplirse con ayuda esterior. ¿Puede i quiere Chile prestarnos esta ayuda? That is the question. Asegúrelo con hechos positivos i tangibles, i nos tendrá cuerpo i alma en la lucha. Si no, a lo menos por mi parte, consideraría como un crimen emplear la misma influencia de que pueda disponer en precipitar un movimiento sin más garantías que vagas i hermosas promesas de hacerlo todo por nosotros, si damos pruebas positivas. Hablemos claro, una vez levantado el bloqueo i trasladada la guerra a nuestro suelo, ¿se acordará Chile de nosotros? Con su especie de doctrina de Monroe que le es propia, ¿se acordó siquiera de que existía Santo Domingo, durante los tres años de su heroica contienda? ¿Qué hizo por el Perú el año pasado? (...) nada más que mantenerse en estricta neutralidad, (...) He dicho lo que antecede para probar que fuera de un interés platónico de amor a la libertad i a las instituciones republicanas, nada tenemos que esperar de Chile, el día que no se vea arrastrado a protegernos por sus propios males. (...) No teniendo, pues, que esperar de Chile más que aquello a que lo obligue la palabra empeñada, ofrézcanos algo positivo i tangible y si es bastante para emprender la revolución se hará inmediatamente" (Vicuña, 1867: II, 146-150).

Basora tenía razón cuando afirmaba que el gobierno chileno nada había dicho a favor de los dominicanos que en 1863 habían iniciado una rebelión armada contra la ocupación de su patria por España y que a la fecha ya habían logrado expulsar al invasor. También era verdad que ante el conflicto generado en el Perú por la ocupación de sus islas el gobierno se había declarado formalmente neutral.

En realidad, el americanismo que por entonces impregnaba a la sociedad chilena tenía disímiles expresiones. El gobierno en su momento se había preocupado por la anexión de Santo Domingo y aún más ante la ocupación de México. Finalmente, ante la ocupación de las Chincha, proclamaría su más irrestricto apoyo al Perú, no obstante su declaración de neutralidad (López, 2011: 72-78; 99-106; 133-139). Sin embargo, entre 1861 y 1865 , quienes con más fuerza enarbolarían las banderas del americanismo serían los miembros de la oposición al gobierno y ciertos sectores medios urbanos sensibles ante los acontecimientos en Hispanoamérica. A lo largo del período, la oposición - de la cual había formado parte Vicuña- presionó de manera constante y creciente al gobierno para que asumiera una actitud más decidida ante las intervenciones. Sin embargo, éste, a pesar de sostener una retórica americanista, había sido más bien cauteloso, y más aún cuando a partir de 1864 se le hizo evidente que corría el serio riesgo de que el conflicto hispano-peruano condujera al país a una guerra con España. Al contrario, la oposición -predominantemente liberal-, agrupada 
en asociaciones de tanto peso político como la Sociedad Unión Americana de Santiago ${ }^{7}$, había promovido un fuerte sentimiento americanista en parte de la población, que sobre todo ante la ocupación de las Chincha exigió que Chile fuera a la guerra con España, algo que vanamente intentó evadir el gobierno. Sólo cuando la guerra le resultó inevitable, había asumido como propios los postulados de los americanistas de la oposición y a varios de sus representantes los colocó al frente de las tareas orientadas a hacer del conflicto una guerra americana ${ }^{8}$, entre los cuales estaba el ahora flamante Agente Confidencial en los Estados Unidos. Por ello, no sin razón, el primer encuentro entre el representante chileno y los independentistas antillanos había sido áspero.

Sin embargo, las mutuas suspicacias iniciales no les impidieron persistir en mantener una relación que de alguna manera hiciera efectivos los ofrecimientos de ayuda de Chile. La colaboración condujo a que el 8 de febrero Vicuña le informara al ministro de Relaciones Exteriores chileno, Álvaro Covarrubias, que "algo se prepara en Cuba". Indicaba que Macías le había entregado un plan para una expedición revolucionaria y que para ello solicitaba cien mil pesos (Vicuña, 1867: II, 153). También La Voz de la América comenzaba a cumplir su objetivo. El 16 de febrero, el matancero Ignacio Mendoza informaba a Macías que "Como en mi última le pedía me remitiera algunos ejemplares de La Voz de América y no los he recibido, le reitero la petición porque me sacan los ojos por ellos creyendo que los recibo". ${ }^{9}$ Por otra parte, el 9 de marzo el agente chileno le planteaba al ministro Covarrubias la idea de enviar un "comisario" a Santo Domingo, pues "El estado de guerra no ha cesado entre ese país i España, (...) i por lo que me aseguran (...) no sería difícil organizar una expedición i lanzarla sobre Puerto Rico..." (Vicuña, 1867: II, 155). También el 20 de marzo le escribía planteándole la idea de apoyar un desembarco sobre Cuba:

7 Entre los miembros de la Sociedad de Santiago se encontraban Benjamín Vicuña Mackenna, Manuel Antonio y Guillermo Matta, José Victorino Lastarria, Miguel Luis Amunátegui, Isidoro Errázuriz, Domingo Santa María, Álvaro Covarrubias, Ángel Custodio y Pedro León Gallo, Marcial Martínez, Francisco Ignacio Ossa, Manuel Antonio Tocornal, Antonio Varas y José Agustín Palazuelos. Casi todos liberales y llamados a jugar un papel relevante en la historia de Chile de la segunda mitad del siglo XIX.

8 Sus primeras iniciativas apuntaron a obtener el apoyo de los países hispanoamericanos y de los Estados Unidos. A esos efectos contaba con el Ministro Plenipotenciario ante la Argentina, Brasil y Uruguay, José Victorino Lastarria, y con el Encargado de Negocios ante Ecuador, José Nicolás Hurtado. Además nombró a Manuel Antonio Matta como Encargado de Negocios ante los gobiernos de Colombia y Venezuela, y a Álvaro Covarrubias como ministro de Relaciones Exteriores.

9 Correspondencia de Ignacio Mendoza a Juan Manuel Macías, Matanzas, 16 de febrero de 1866. AHN. FMRE. Volumen No. 127. 
"La convicción general aún entre los más exaltados patriotas cubanos en ésta, es, que la base de una insurrección llamada a independizar a Cuba es el apoyo de una espedición esterior, que no puede salir sino de Nueva Granada, de Venezuela o de Santo Domingo. (...) En el sentido de preparar esas espediciones, creo, en mi humilde juicio, que deberían empeñarse los ajentes del gobierno de Chile i del Perú, en los estados de Colombia. Yo por mi parte, en lo que está en mis alcances hago cuanto me es dable en este sentido" (Vicuña, 1867: II, 155-157).

Pero además, como parte de su política para enfrentar la guerra con España, Chile se había propuesto armar corsarios, y Vicuña era portador de varias patentes para habilitarlos. Por ello no podía dejar de ser estimulante saber que desde La Habana le escribieran el 23 de marzo a Macías, diciéndole: "Querido amigo: Es de indispensable necesidad que a vuelta de correo me remita una patente de corso chilena, todo está preparado y sólo espero ese documento para salir a la mar".$^{10}$ Por su parte, el Cónsul chileno en Saint Thomas (Islas Vírgenes) informaba el 24 de marzo al agente chileno que "En Puerto Rico es tal el pánico de Corsarios que los comerciantes españoles embarcan los frutos de la isla solamente en cascos extranjeros y bajo conocimiento de casas forasteras (...)"11. Sin embargo, la relación de Chile con los antillanos cambió cuando finalmente el 31 de marzo la escuadra española bombardeó Valparaíso.

La política americanista del gobierno para enfrentar la guerra con España no pudo evitar el peor de los escenarios posibles. Pero además el bombardeo determinó que el americanismo dejara de operar sobre su conducta para enfrentar la guerra, más aún cuando por efecto de la partida de la escuadra12, no había enemigo con quien combatir. El 9 de abril, el ministro de Relaciones Exteriores le informó a Vicuña que "el gobierno ha resuelto poner fin a la comisión que desempeñaba Ud. en ese país" y le solicitaba regresar a la brevedad (Vicuña, 1867: II, 90).

Sin embargo, mientras Vicuña permaneció en los Estados Unidos, su correspondencia con el ministro Covarrubias continuaría refiriéndose a sus planes para contribuir a la independencia de las Antillas. El 20 de abril le

10 Correspondencia a Juan Manuel Macías. La Habana, 23 de marzo de 1866 (documento sin firma). AHN. FMRE. Volumen $N^{\circ} 127$.

11 Correspondencia de Hipólito Victoria a Benjamín Vicuña Mackenna, Saint Thomas, 24 de mayo de 1866. AN. FMRE. Volumen № 127.

12 Tras bombardear Valparaíso, la escuadra se dirigió al Callao, con la intención de hacer lo mismo con ese puerto. Sin embargo, a diferencia del chileno, el puerto del Callao contaba con un importante sistema defensivo, que el 2 de mayo respondió con efectividad al ataque de la escuadra. Posteriormente, las fuerzas españolas abandonaron el Pacífico. 
escribía proponiéndole realizar una expedición chileno-peruana de dos mil hombres sobre Cuba. Su idea era preparar "una expedición que fuese, más bien que un ejército, una escolta suficiente para llevar veinte mil fusiles al corazón de la isla". De paso, también le recordaba que "en su manifiesto hizo esta promesa a las naciones a que lo dirijió, i que si los españoles han cometido algún acto de barbarie en nuestras costas el presente sería el mejor momento para cumplirla"13. Quizá la proposición pudo parecerle descabellada al gobierno, pero no a los independentistas cubanos, que ya habían recibido del agente la solicitud de un plan de desembarco. ${ }^{14}$ Un mes después, el cubano Cayetano Quesada le escribía demandándole recursos para una insurrección:

"el siguiente encargo importante que me dieron varias personas de influencia, representabilidad y crédito militar en La Habana. (...) Mil fusiles con sus correspondientes municiones, etc. bastarían y es todo lo que aquellos patriotas piden a sus hermanos chilenos para un movimiento que tantos beneficios traería a nuestra común patria la América. Y no es que pidamos gratuitamente los mil fusiles, pues si Cuba conquista su independencia, esa será una deuda demasiado sagrada para que jamás pueda olvidarla" ${ }^{15}$.

Pero por entonces el gobierno chileno ya no tenía en sus expectativas sublevar a las Antillas. A fines de junio Vicuña ya se encontraba en camino a su patria. Antes de partir, a nombre de los compromisos de su país, había entregado a la Sociedad Republicana de Cuba y Puerto Rico quinientos pesos "que reunidos a otros 500 que había colectado aquella institución sirvieran para enviar a la isla cien carabinas de Sharp que se pedían para armar una guerrilla" (Vicuña, 1867: II, 91). Tras su partida, el Encargado de Negocios en Washington, Francisco Solano Astaburuaga, sostuvo durante algún tiempo los contactos con la Sociedad. Por su iniciativa, el gobierno siguió financiando La Voz de la América. Sin embargo, a pesar de que la opinión del diplomático era de que "sería de pésimo efecto (...) la cesación de ese periódico, que haría creer que no éramos ni aun capaces de sostener ese medio de hostigar a la

13 Oficio de Benjamín Vicuña Mackenna al ministro de Relaciones Exteriores chileno; Nueva York, 20 de abril de 1866. AHN. FMRE., vol. 127, s/n.

14 El 30 de abril Macías se dirigía a Vicuña, presentándole un informe "sobre el punto de la isla de Cuba en que (...) pueda y deba hacerse un desembarco de tropas revolucionarias". El cubano proponía la costa de Cienfuegos para realizar el desembarco. Al respecto ver el "Informe que presenta el señor Juan Manuel Macías al señor Benjamín Vicuña Mackenna, Agente Confidencial de Chile en los Estados Unidos de América, sobre una expedición militar para hostigar a España en sus colonias, favoreciendo a los revolucionarios de la isla de Cuba y teniendo presente que la dicha expedición, por circunstancias particulares, deberá desembarcar por la parte sur de aquella isla." Nueva York, 30 de abril de 1866. AHN. FMRE., vol. 127, s/n.

15 Correspondencia de Cayetano V. Quesada a Benjamín Vicuña Mackenna, Nueva York, 29 de mayo de 1866. AHN. FMRE., vol. 127, s/n. 
España"16, el subsidio al órgano independentista sólo duraría algunos meses. El 23 de febrero de 1867, el nuevo embajador de Chile en los Estados Unidos, Alberto Blest Gana, comunicaba oficialmente al editor del periódico que su gobierno había decidido suspender la subvención de cuatrocientos pesos que se le tenía otorgada ${ }^{17}$. El gobierno de Chile terminaba así su relación con el independentismo antillano. $\mathrm{O}$ al menos eso creía.

\section{La sublevación de la isla y las responsabilidades pendientes}

El 10 de octubre de 1868, en Santiago, Isidoro Errázuriz, ante dos mil personas recordaba cómo en 1865 el gobierno había promovido, en Cuba y Puerto Rico, "excitaciones poderosas i manifestaciones armadas, prometiendo a esos pueblos desgraciados el apoyo de corsarios imaginarios e inflamándolos por medio de un periódico fundado con tal objeto". Y agregaba, "sangre americana corrió en esos países, en obsequio de la vanidad i por culpa de la lijereza i la deslealtad del gobierno de nuestra república" (El Ferrocarril, 1868). El encuentro era parte de la confrontación entre el liberalismo de oposición y el gobierno. Sin amenazas a la soberanía del país y del continente sobre el horizonte, las élites se concentraban en debatir el modelo político que aspiraban para su país. En ese contexto, para los liberales, recordar el apoyo que el gobierno ofreciera a los independentistas de las Antillas, constituía un recurso más para descalificarlo. Lo que no sabía Errázuriz es que ese mismo día el cubano Carlos Manuel de Céspedes iniciaba la primera guerra de independencia de su patria.

La noticia de la insurrección no dejó indiferente a una parte de las élites chilenas. El 29 de abril de 1869, el diputado José Victorino Lastarria interpeló al ministro de Relaciones Exteriores, Miguel Luis Amunátegui, respecto a la posición del gobierno frente al movimiento independentista cubano. Al mismo tiempo, Cuba pasó a ser el centro de los debates de la prensa. El editorial de El Independiente del $1^{\circ}$ de mayo así lo reflejó:

"Chile debe hacer en favor de los patriotas de Cuba cuanto racionalmente esté en la posibilidad de hacer. La cuestión no puede ser de principios ni de sentimientos, sino de medios... (...) Hasta aquí lo que algunos órganos de la prensa han reclamado es que se reconozca a los patriotas, no sólo los derechos de belijerantes, sino también su

16 Correspondencia de Francisco Astaburuaga al Ministro de Relaciones Exteriores de Chile, Nueva York, 20 de septiembre de 1866. AHN. FMRE., vol. 134, foj. s/n.

17 Correspondencia de Alberto Blest Gana al Ministro de Relaciones Exteriores de Chile, Washington, 27 de febrero de 1867. AHN. FMRE., vol. 134, foj. s/n. 
autonomía i personalidad internacional. (...) ¿Podemos hacer algo más? (...) Nuestra obligación es tanto más estrecha cuanto que fuimos de aquellos que excitamos a los cubanos a iniciar la gloriosa empresa en que hoi se encuentran comprometidos" (El Independiente, 1869).

Tres días después, el debate sobre Cuba en la Cámara de Diputados mostró las distintas perspectivas que podían asumirse respecto al apoyo a los insurrectos. En respuesta a la primera pregunta de Lastarria, "¿Qué piensa el gobierno de Chile de la independencia de Cuba?", el ministro de Relaciones Exteriores manifestó que, por supuesto, el gobierno simpatizaba con el derecho de los cubanos de separarse de España, tal como lo habían hecho anteriormente los países de Hispanoamérica. No obstante, a su juicio, la pregunta también podía ser interpretada en términos de si el gobierno estaba dispuesto a reconocer la independencia de la isla. Y al respecto señaló: "el gobierno de Chile no se creería autorizado para dar por existente lo que no existe. (...) El gobierno de Chile no puede reconocerla por la misma razón porque no la ha reconocido hasta ahora uno solo de los otros gobiernos de América: porque no existe" (Sesiones del Congreso, 1869: 71). En su opinión, en Cuba hasta ese momento sólo había una lucha entre los partidarios de dos formas de régimen político. La victoria de uno u otro decidiría cuál sería finalmente el adoptado. Por otra parte, segunda interrogante de Lastarria era, "¿Qué ha hecho el gobierno en favor de los revolucionarios o patriotas cubanos?" Amunátegui leyó entonces la carta que enviara al gobierno Carlos Manuel de Céspedes, Capitán General del Ejército Libertador de Cuba, el 9 de diciembre de 1868. En ella reseñaba el inicio de la guerra por la independencia, la amplitud que iba alcanzando, la conformación de un gobierno provisional republicano en la ciudad de Bayamo, y solicitaba el reconocimiento de los insurrectos como beligerantes, además de los buenos oficios del país para evitar las depredaciones de las fuerzas españolas en el contexto de la guerra. El gobierno le había respondido reconociendo el carácter de beligerantes de los independentistas y le informaba que había oficiado a sus representantes diplomáticos en Washington y Lima para que expresaran los deseos de Chile de que Estados Unidos influyese sobre España para la regularización de la guerra en Cuba (Sesiones del Congreso, 1869: 72-73). Y eso era todo.

Lastarria fue el primero en cuestionar las respuestas del ministro. Para el diputado se requería que Chile reconociera la independencia de la isla: "¿Hai, acaso, algún gobierno americano que tenga más responsabilidad respecto de ese acto que el de Chile? (...) Su deber le ordena reconocerla" (Sesiones del Congreso, 1869: 73). Para Marcial Martínez, era "...necesario no olvidad que Chile prometió de una manera solemne hacer independientes a los cubanos", (Sesiones del Congreso, 1869: 74). Vicuña Mackenna recordó que Chile aún estaba en guerra con España "...i, sin embargo discutimos a favor de Cuba como si las medidas que deben tomarse fueran a herir a 
una potencia amiga", y agregó: "El gobierno de Chile está vinculado a esta empresa por muchos antecedentes..." (Sesiones del Congreso, 1869: 75). Finalmente, para Manuel Antonio Matta los acontecimientos en Cuba no sólo emanaban del desarrollo histórico de su pueblo, sino "... de las promesas i de los hechos mismos del Gobierno de Chile (...) nosotros hemos impulsado a los cubanos..." (Sesiones del Congreso, 1869: 75-76).

El debate reflejó que hacia 1869 una parte de las élites políticas sostenía aún un americanismo en la lógica del período 1861-1865. Los cuestionamientos al gobierno provenían de aquellos que, de distintas maneras, habían participado del apoyo ofrecido por Chile a los independentistas cubanos. Pero para el gobierno y para la mayor parte de las élites, si lo que se pedía era reconocer la condición de beligerantes de los insurrectos, pues se hacía al pie de la letra de la carta de Céspedes, tomando además las providencias justas conforme a lo demandado (los oficios a los embajadores ante los Estados Unidos y el Perú). Si había simpatía con la causa cubana, ésta pasaba por la historia de la independencia chilena. La cubana era similar, en voluntad y espíritu, pero en ningún caso se hacía referencia a la relación de Chile y su gobierno con el independentismo de 1865. Por sobre cualquier compromiso, parecía que lo importante era no alterar el proceso que se había iniciado con el bombardeo a Valparaíso: buscar la paz con España ${ }^{18}$, y buscar simultáneamente la "paz" interior del país. Y para ello era necesario soslayar cualquier expresión solidaria anterior con las Antillas.

Por otra parte, también la prensa entró en el debate. El editorial del 7 de mayo de El Independiente opinaba que "Chile, en guerra con España, no ha hecho por Cuba absolutamente nada más de lo que debía haber hecho estando en paz con la España". Luego, para el periódico, en la Cámara no se había hecho todo lo posible para respaldar a los insurrectos. Para el periódico el problema seguía abierto, y era sobre todo responsabilidad del gobierno enfrentarlo, como también de los países miembros de la alianza del Pacífico (El Independiente, 1869a). Por su parte, el mismo día El Mercurio contemporizaba con el gobierno. Para su editorial, la postura del ministro Amunátegui era la más acertada, atendiendo a las negociaciones que se venían desarrollando con España. "Por muy digna que sea la independencia de Cuba de las simpatías de todas las repúblicas, no creemos que se podría exijir de Chile que hiciese por ella lo que no ha hecho por él", señalaba el periódico, refiriéndose a los que proponían reiniciar las hostilidades contra España. "La insurrección cubana ha venido demasiado tarde, cuando las repúblicas aliadas han aceptado la mediación de los Estados Unidos" (El Mercurio,

18 Junto con los países de la alianza generada con motivo de la Guerra con España, el gobierno desde hacía poco se encontraba -con la mediación de los Estados Unidos- negociando con su enemigo un acuerdo de tregua. 
1869). Al día siguiente la opinión de La República también se identificaba con las medidas tomadas por el ministro Amunátegui, pero las justificaba en la "cordura" del gobierno. "Si se puede hacer algo por nuestros hermanos de Cuba, se hará; pero entre las naciones (...) no se puede obedecer los ímpetus de una abnegación sin límites,...". Y sentenciaba: "Dejemos algún día de hacer política de corazón i hagámosla administrativa. Reconózcase por lo menos el deber i el derecho en que está un gabinete de substraerse a los calores de la idea i a las fogosidades de la hora" (La República, 1869). Al día siguiente insistía sobre la cuestión cubana, discutiendo con los que pretendían un apoyo armado a los independentistas:

"las espediciones lejanas son sinónimos de fuertes desembolsos. A duras penas damos abasto a las exijencias del país mismo, i se indica que acometamos formidables empresas que comprometerían nuestra honra poniéndonos en angustias para el pago de nuestros compromisos pecuniarios i que nos obligarían a empeñar todavía más nuestro porvenir. (...) Persuádanse los diaristas de la oposición que parecen andar en busca de conflictos para los buques que tenemos, lo que los cubanos han menester por ahora no son naves débiles i escasas sino aquellos tres elementos que un famoso jeneral juzgara esenciales para la guerra: oro, oro i oro" (La República, 1869a).

Y dicho esto, La República convocaba a los periódicos, clubes, y a la opinión pública a una suscripción en apoyo de los republicanos cubanos. De alguna manera dejaba también todo claro. Primero, que del gobierno no habrían más acciones en apoyo a Cuba que las realizadas. Y segundo -aunque sin decirlo directamente-, que el pasado americanista había sido producto de ímpetus de una abnegación sin límites, una política del corazón, y el efecto de los calores de la idea y de las fogosidades de la hora; y eso, no era cuerdo ni aceptable.

No sabemos si la propuesta de La República fructificó. Pero un intento de llevar a hecho la solidaridad con Cuba vino del Club de la Reforma ${ }^{19}$. Un aviso en El Ferrocarril invitaba a sus miembros " $\mathrm{i}$ a todas las personas amigas de la libre discusión" a una conferencia para el 17 de mayo. Los temas de la conferencia serían "10: Chile i la América en presencia de la insurrección de Cuba", y el segundo -doméstico, liberal, y propio de la oposición al

19 El Club de la Reforma había sido fundado en 1868. Reunía a ciertos sectores liberales disidentes del gobierno, a algunos miembros del Partido Radical, y también a conservadores monttvaristas. Todos sus adherentes compartían el encontrarse al margen del gobierno, y la aspiración común (y liberal) de modernizar y democratizar la sociedad de entonces. Varios de ellos -como Lastarria, Santa María, Antonio Varas, Manuel Recabarren y Pedro León Gallo- habían sido "viejos" americanistas y miembros de la Sociedad Unión Americana. Al respecto ver (Gazmuri, 1992: 149-157). 
gobierno- "Interés de la causa de la libertad i de la reforma en el desenlace de la acusación a la Corte Suprema" (El Ferrocarril, 1869a). El primero de los temas fue abordado por José Manuel Balmaceda. El editorial del día 18 de El Ferrocarril resumió sus palabras: "Con la incisiva elocuencia que lo caracteriza, el orador hizo una reseña de la situación de Cuba i, recordando las promesas hechas por nuestro gobierno en no lejanos tiempos, concluyó por manifestar que Chile o su gobierno estaban mui distantes de haber cumplido sus compromisos ni su deber como americanos" (El Ferrocarril, 1869b). Esta sería la tónica que seguirían los siguientes oradores, Isidoro Errázuriz y Domingo Arteaga Alemparte; es decir, atacar al gobierno, destacando su inconsecuencia ante los compromisos que había asumido cuatro años antes. Errázuriz llegó a proponer, puesto que el gobierno no pretendía apoyar a los insurrectos con las armas, "que se borraran del presupuesto los ítems del abuso, los de la guardia cívica (...) para enviar un millón de oro a nuestros hermanos de Cuba..." (El Ferrocarril, 1869b). Con posterioridad, el 30 de mayo, durante las actividades de agitación que organizara el Club de la Reforma en la ciudad de Curicó, un grupo de personalidades locales propusieron que se promoviera en esa ciudad y en el país "un movimiento de opinión enérgico en favor de la independencia de Cuba, i una suscripción en favor de aquella independencia", designándose una comisión para recoger los aportes que se realizaran (El Ferrocarril, 1869c). Sin embargo, durante el año no acontecerían nuevas expresiones de solidaridad con Cuba. Las prioridades políticas entre las élites chilenas estaban lejos del tema cubano. El centro de sus preocupaciones estaba en debatir sus diferencias. Únicamente en ello.

\section{Una solidaridad en la medida de lo posible}

No obstante, Cuba volvió a la palestra con motivo del debate parlamentario para la ratificación del Tratado que conduciría a una tregua indefinida entre Chile y España. Entre el 3 y el 28 de octubre de 1871 fue discutido en la Cámara de Diputados. Parte de la oposición al gobierno lo objetó por considerarlo en la práctica un acuerdo de paz, que no involucraba ninguna reparación por el bombardeo a Valparaíso y porque desconocía los compromisos de Chile con Cuba, ya hacía tres años insurrecta. En la sesión del día 19 el Ministro del Interior, Eulogio Altamirano, intervino refutando los cuestionamientos al acuerdo. Respecto a las promesas y declaraciones hechas a los independentistas antillanos durante la guerra con España, dijo el ministro:

"Prescindamos de la exaltación natural conque esas palabras debieron ser escritas, i esas dilijencias practicadas. (...) Andando los acontecimientos, Chile, sea por falta de recursos, sea por los motivos que se den, no cooperó a la independencia i libertad de Cuba. (...) ¿Esto significaría que hemos salido vencidos en la guerra con España? (...) 
¡No señores! La guerra entre las repúblicas del Pacífico i la España tuvo por orijen i principal objeto, una cuestión de supremacía ilejítima que la segunda pretendía arrogarse sobre la primera, i no la independencia de Cuba. (...) La emancipación de la reina de las Antillas fue sólo una cuestión adventicia. (...) No puede sostenerse que el último levantamiento de Cuba haya tenido lugar a la voz de Chile, i que por lo tanto, nuestro país hubiese contraído una obligación especial para ausiliarlo" (Sesiones del Congreso, 1871: 322).

No había promesas incumplidas. Sólo un poco de exaltación en el pasado. La mayoría de los parlamentarios aprobaron en Tratado de Tregua, cerrando en la práctica la posibilidad de que Cuba encontrara en el gobierno un respaldo explícito a su causa. Las siguientes visitas de antillanos independentistas así lo ratificarían, tal como aconteció con la llegada a Chile, el 30 de diciembre, del puertorriqueño Eugenio María de Hostos, una figura estrechamente relacionada desde 1869 con Basora y la Junta Revolucionaria Cubana de Nueva York, organizada a partir del alzamiento de Céspedes (Araya, 1967: 11).

Con motivo de esta visita, durante la primera semana de octubre de 1872 la prensa de Santiago dio difusión a la convocatoria "para una reunión en favor de Cuba". Se llamaba a celebrar de manera solemne el cuarto aniversario del inicio de la insurrección. El encuentro se realizó en el Club de la Reforma el 10 de octubre, en presencia de seiscientas personas (El Independiente, 1872). Hostos cerró la reunión con un discurso donde con sutileza cuestionó la conducta seguida por Chile respecto a sus compromisos de 1865 . El puertorriqueño recordó los esfuerzos del país en 1820 por contribuir, a través de una escuadra libertadora, a la independencia del Perú. "Y entonces Chile acababa de nacer - dijo-i era débil i pudo; i hoi que ha empleado bien sus años i que es fuerte, jnada puede!" (El Ferrocarril, 1872). Su discreta crítica daba cuenta de la importante mutación cultural que estaba aconteciendo dentro de las élites chilenas respecto a Hispanoamérica y el americanismo solidario.

Esto último también se estaba reflejando en la polémica suscitada por entonces a raíz de la convocatoria para un congreso hispanoamericano en Lima. La propuesta, que contemplaba la fundación de un derecho internacional propio para el continente, dividió los criterios de las élites, lo cual fue recogido por la opinión de la prensa. El editorial de El Mercurio del 8 de octubre abrió los fuegos sobre la convocatoria al preguntar "¿qué clase de derecho internacional americano es aquel que puede formarse entre países que, aún unidos por origen, lengua, costumbre, están todavía mui ajenos de reconocer esa unión como un lazo indisoluble?". El editorial juzgaba también los congresos unionistas celebrados hasta entonces como inoperantes, y sin fuerza para incidir en los acontecimientos de la región. De esta manera, la unidad latinoamericana era sólo una quimera. Y sentenciaba el editorial: 
"Gobernemos bien en nuestra casa i dejemos que cada cual sea responsable de sus actos. Esto no es proclamar la doctrina del egoísmo sino sostener el principio de la libertad de acción de cada pueblo,..." (El Mercurio, 1872). Al día siguiente La República sostenía la línea de su colega al afirmar en su editorial: "Supóngase existente el congreso americano. Para que surtiera el efecto que se proponen los que lo reclaman, sería menester que creáramos una especie de tribunal sin apelación posible de sus fallos. (...) ¿Iría una nación a someter a su juicio lo que considerase su derecho?" (La República, 1872). Pero el que más opuesto a la idea de un congreso hispanoamericano era El Independiente. En su editorial del 10 de octubre calificaba a quienes compartían el proyecto unionista de antipatriotas y descabellados. Aceptarlo significaría renunciar a una parte de la soberanía del país. Además, subrayaba lo que a su entender debía ser la posición de Chile ante los acontecimientos que se desarrollaran fuera de sus fronteras:

"la política que en general nos conviene observar, es la misma que ha hecho la prosperidad de Inglaterra, es decir, la política de abstención. De ella no debemos salir, sino cuando la abstención implique para nosotros un peligro real e inmediato. Fuera de ese caso, debemos limitarnos a gobernar bien nuestra casa,... (...) Donde los intereses de Chile no están positiva i directamente comprometidos, Chile no debe aventurar sus intereses. (...) lo repetimos, la base de nuestra política internacional debe ser el egoísmo; el egoísmo ilustrado, intelijente, perspicaz, pero el egoísmo" (El Independiente, 1872).

Solo El Ferrocarril sostendría un criterio discordante, preguntándose "¿Qué provecho sacan los Estados de América de sus rivalidades? ¿Arrancan grandeza, gloria, fuerza, respetabilidad siquiera? (...) el antagonismo es una insensatez y se necesita solo un minuto de buen sentido para que concluya" (El Ferrocarril, 1872a). La discusión era sintomática del cambio que se venía gestando al interior de los gobernantes chilenos y de la mayoría de las élites. De alguna manera se comenzaba a percibir al país distinto al resto de su entorno hispanoamericano. El desarrollo de esta cultura de la diferenciación ya impregnaba en distintos grados y de distintas maneras a prácticamente todas las élites. De ellas, solo un sector sostenía una proyección americanista en sus reflexiones y prácticas, eventualmente con fuerza suficiente como para arrastrar al resto de sus pares, en función de una postura opuesta a la cultura del "egoísmo", del cual se hablara en uno de los editoriales ${ }^{20}$.

20 Este cambio es percibido por Mario Barros Van Buren: "entre 1866 y 1871 comienza a gestarse en Chile un sentimiento que conviene conocer. La generación que en 1866 presenció nuestra miseria frente al cañón europeo, por un lado, y frente a la soledad chilena, por otro, descubrió la urgente necesidad de orientar nuestra política exterior hacia un equilibrio de fuerzas. Esta generación tuvo un concepto mucho más frío de la realidad americana. Y 
Ello se hizo evidente cuando el 20 de agosto de 1874 llegó a Chile el General del Ejército Libertador cubano Manuel de Quesada, presidiendo una delegación. Sin duda, a los americanistas se les planteó el dilema de cómo expresar su solidaridad con las visitas, en un contexto en que el tema antillano no estaba en la agenda de las élites. Otra recién llegada les daría la solución. Cinco días antes del arribo de los cubanos, lo había hecho la actriz dramática e intérprete italiana Adelaida Ristori. Su llegada estuvo precedida por grandes y rimbombantes comentarios acerca de sus virtudes como artista. El Ferrocarril del 23 de agosto le dedicaba un amplio editorial alabando sus condiciones y trayectoria. También en esa edición aparecía una pequeña nota donde se anunciaba que ese día el Intendente de Santiago, Vicuña Mackenna, daría un banquete en honor de la diva, al que asistirían todos los ministros, los presidentes de las Cámaras, y los representantes diplomáticos de Italia. Al final se indicaba que "el distinguido general cubano Quesada y el doctor Zambrana, de La Habana, asistirán también a este banquete." (El Ferrocarril, 1874). Reunidos todos los invitados y la principal homenajeada, los primeros brindis fueron en su honor. Sin embargo, el anfitrión, llegado su turno, se dirigió a los comensales señalando que entre ellos se encontraba el "ilustre general en jefe de las tropas libres de Cuba", Manuel de Quesada. Hizo entonces una breve reseña de su vida, y agregó:

"Y en vista de esto señores, i de lo que pasa cada día, cada hora, en el suelo en que nació i sucumbió el glorioso Céspedes, ¿Chile podría manifestarse eternamente indiferente...? (...) No señores. Yo soi un funcionario público, y me caben por ello ciertos deberes inexcusables; pero también soi ciudadano, i como tal he convocado a este peñón [el banquete se celebraba en el Cerro Santa Lucía] a mis más antiguos i más queridos amigos. A ellos me asociaré. Guillermo Matta, el coronel Saavedra, Luis Pereira, Melchor Concha i Toro, los dos Arteaga Alemparte, todos los que aquí me acompañan me ayudarán a promover en la capital un meeting colosal que tenga lugar en este gran anfiteatro del pueblo chileno, el domingo próximo. Aquí... (...) escucharemos la relación palpitante de los dolores de Cuba contados por sus propios hijos, (...) por el patriota, por el soldado. I a esas voces unirán las suyas todos los que sientan los santos impulsos del amor a la patria i al culto de la libertad" (El Ferrocarril, 1874a).

Vicuña Mackenna lograba así convocar el apoyo a la independencia cubana en un contexto donde hasta los representantes del gobierno se veían en la situación de aplaudir y respaldar la iniciativa. El 26 aparecía en la prensa santia-

mucho más duro. (...) Los hombres de 1866 volvieron violentamente al concepto portaleano de "primero Chile y luego veremos" (Barros, 1970: 278). 
guina la convocatoria al meeting de solidaridad convocado por el Intendente, que se celebraría el domingo en el Teatro Municipal, continuándose luego en el cerro Santa Lucía. También los otros periódicos de la capital dedicarían sus editoriales y comentarios a respaldar el movimiento de solidaridad con Cuba (El Mercurio, 1874a; El Ferrocarril, 1874b; El Independiente, 1874). El acto fue, a juicio de la prensa, exitoso. Dirigieron la palabra Zambrana, Quesada, Guillermo Matta y Eduardo de la Barra. También participó en el encuentro, como no, Adelaida Ristori (El Ferrocarril, 1874c).

En Valparaíso también se hacían preparativos para un acto similar al de Santiago. El $1^{\circ}$ de septiembre Quesada y Zambrana se trasladaron al puerto. A su llegada, los cubanos fueron recibidos en la estación por "ciento y tantos jóvenes y una banda de música". En medio de vivas a Cuba y de aires marciales fueron acompañados hasta el Hotel Colón, donde se hospedaron ( $E$ I Mercurio, 1874b). El encuentro se celebró el sábado 6 en el Teatro Victoria. Había sido convocado por un grupo de personas encabezadas por Juan de Dios Arlegui. Asistirían más de tres mil personas (El Ferrocarril, 1874d). A su término se nombró una comisión para solicitarle al Congreso y al Presidente de la República que acordaran la suma de pesos con que el gobierno de Chile "socorrerá a los heridos, a las viudas y a los huérfanos del ejército cubano". Además, a ambos poderes se les solicitaba que convocasen un congreso americano "para promover la intervención de los pueblos civilizados para poner término a los horrores" de la guerra. Se acordó finalmente procurar que en todo el país se desarrollase un movimiento de solidaridad y en respaldo a las solicitudes hechas a los poderes ejecutivo y legislativo (El Mercurio, 1874c).

Esto último ya estaba sucediendo. El mismo día del meeting en Valparaíso, en la prensa de Quillota aparecía una convocatoria en la que se anunciaba que el lunes 8 pasarían por la ciudad, camino a Santiago, los cubanos Quesada y Zambrana. "Con este motivo, muchos vecinos del departamento se preparan para dar una manifestación de sus simpatías al jeneral en jefe de los ejércitos de Cuba, yendo a recibirle a la estación central..." La convocatoria agregaba que también se les invitaría al teatro de la ciudad "a fin de expresarle de viva voz lo que puede esperar del pueblo de Quillota en pro de la digna causa que sostiene". Firmaban el llamado Baldomero Riso Patrón -presidente de la comisión encargada del recibimiento-, Pedro N. Cobo, y Pedro J. Mena, entre otros (El Correo de Quillota, 1874). Los cubanos permanecieron tres días en Quillota, donde serían ampliamente agasajados por la élite de la ciudad. Su partida también se transformaría en un nuevo acto de solidaridad, concurriendo a despedirlos "lo más selecto y respetable de nuestra sociedad" (El Correo de Quillota, 1874a).

Pero además no era imprescindible la presencia de los cubanos para que se suscitasen muestras de solidaridad con su causa. En Valparaíso, el 10 de septiembre se presentaba una función especial del "Circo Imperial Brasilero", "a 
beneficio de los huérfanos i viudas de Cuba". Según El Mercurio, concurrirían al espectáculo "de mil quinientas a dos mil personas". También este periódico anunciaba que se estaba preparando un concierto en beneficio de Cuba (EI Mercurio, 1874d). Tres días después, la Comisión de subsidios en favor de Cuba de Rancagua - presidida por Ramón Sotomayor-acordaba realizar un meeting el domingo 20 en respaldo a la independencia de Cuba. Llegado el día, "...fue sacada de la casa del presidente la bandera cubana junta con la chilena, i paseada por las principales calles de esta ciudad, sirviéndole de escolta una larga fila de vecinos y la banda de música del cuerpo cívico que ejecutó en todo el trayecto de la marcha, variados trozos (El Fénix, 1874). El desfile se dirigió al templo parroquial donde varios rancagüinos dirigieron la palabra a los concurrentes recordando la presencia en Chile de los cubanos Quesada y Zambrana (El Fénix, 1874a). También con las fiestas patrias nuevamente Quillota reiteraría su respaldo con la causa de Cuba. Al baile de celebración de la independencia fue invitado especialmente el general Quesada. En la ocasión "algunas respetables señoras" le obsequiaron una espada con su nombre grabado. Quesada agradecería el gesto recordando, no obstante, las circunstancias de la solidaridad chilena con su patria: "Señoras: esta espada, símbolo de libertad que patriótica i galantemente me ofrecéis, me servirá para redimir a mi pobre patria; (...) así también desearía que Chile armara la mano desarmada de tanto valiente cubano para libertar a su patria, i sería éste el hecho más glorioso de su historia" (El Correo de Quillota, 1874b; El Mercurio, 1874e). Por otra parte, en la ciudad de Concepción también se suscitaba un movimiento de apoyo a la causa cubana. El $1^{\circ}$ de octubre, una comisión, encabezada por Ricardo Claro, Miguel Collao y Felipe Anguita solicitaban a la compañía teatral "De-Paladini y Cavara" un "beneficio" a favor de Cuba. A la respuesta afirmativa de la compañía, se sumaba la renuncia del dueño del teatro a cobrar por su arriendo y la renuncia de la empresa de gas al cobro por el alumbrado del teatro durante la función. Ésta se celebraría el martes 6 de octubre, con un lleno total ( $L a$ Democracia, 1874; La Revista del Sur, 1874). Finalmente, a través de la prensa se informaba con relativa frecuencia acerca del dinero que era recolectado en los meetings, funciones "a beneficio", y por las erogaciones voluntarias que también se hacían. Estos fondos eran recaudados por las comisiones que convocaban a las actividades solidarias, y una vez reunidos, eran "enviados por conducto del banco Edwards i Ca. a la Junta Cubana de Nueva York, por haberlo solicitado así el jeneral Quesada" (El Mercurio, 1874e).

Sin duda, la iniciativa de Vicuña había despertado relevantes expresiones de solidaridad con Cuba, las que demostraban que no obstante el giro de la política del gobierno y de las élites, tendiente a distanciarse de los acontecimientos regionales y del americanismo del período 1861-1865, en parte de ellas, pero sobre todo dentro de importantes sectores medios, este americanismo solidario seguía plenamente vigente, marcando al respecto 
una diferencia entre las perspectivas del gobierno y las conductas de una parte de la sociedad.

De esta diferencia daría testimonio el último de los cubanos independentistas en visitar Chile. El 7 de marzo de 1875 El Ferrocarril anunció la llegada al país de Enrique Piñeyro, "...ajente diplomático de Cuba, debidamente acreditado por el gobierno republicano de la heroica Antilla... " (El Ferrocarril, 1875). Su misión era presentarse ante el gobierno chileno para recabar su apoyo a la causa cubana, y recoger y despachar un arsenal -almacenado en Viña del Mar por el peruano Mariano Ignacio Prado- a Panamá, desde donde sería enviado a Cuba (Márquez, 83, 94-95, 131). Durante los casi tres meses en que Piñeyro permaneció en Chile, se centró en cumplir su misión con el debido sigilo que ésta exigía. Solo un poco antes de partir, fue recibido en La Moneda por el Presidente Federico Errázuriz. De este encuentro el cubano dejó un testimonio decidor de que el gobierno había renunciado a cualquier manifestación de americanismo y solidaridad, no obstante las recientes experiencias sociales al respecto:

"Después de algunos minutos de amena conversación, principalmente de cosas de los Estados Unidos, acerca de las cuales, pues yo de allí venía, me hizo con interés varias preguntas, cuando empecé a hablarle de asuntos de Cuba, no me preguntó cosa alguna, no pidió más explicaciones ni habló más, sino escuchó sin aprobar ni desaprobar. Suspendiendo yo un momento mi pequeño speech dio por terminada la entrevista, alargó la mano y me acompañó unos pasos dentro de la sala, afable, urbano, pero digno y como resuelto de antemano a en nada comprometerse" (Piñeyro, 1980: 372).

"En nada comprometerse" era la opción definitiva del gobierno y de las élites que representaba. Más allá de cualquier expresión de apoyo social hacia Cuba, el "egoísmo ilustrado" operaba sobre todas sus conductas respecto a Hispanoamérica de manera inclaudicable, y ello incluía a Cuba. Por lo demás, el país no volvería a recibir a cubanos independentistas que incomodaran la resolución del gobierno.

\section{Consideraciones finales}

El americanismo chileno se había hecho visible y relevante en el contexto de las intervenciones europeas del período 1861-1865, al punto que se transformó en política de Estado frente a la guerra con España; una política que llevó incluso a que el gobierno se propusiera contribuir a la independencia de las Antillas españolas. Sin embargo pasadas las circunstancias de la guerra y de la amenaza a la soberanía de los países hispanoamericanos, desaparecieron las condiciones que habían determinado que ese ameri- 
canismo resultara relevante para el gobierno y las élites chilenas. A partir de ese momento, ambos iban a retrotraerse a los debates propios de una comunidad patricia que aún no había llegado a un consenso respecto al proyecto societal del país que unos administraban y que otros aspiraban a hacerlo.

Sin embargo, la primera guerra de independencia cubana y las demandas de los insurrectos de una solidaridad efectiva puso en evidencia que el americanismo era más que una política circunstancial. También era una expresión identitaria que al impulso de la guerra cubana iba a expresarse en un segmento minoritario de las élites. Los debates alrededor del estatus de beligerantes de los independentistas antillanos y acerca del Tratado de tregua indefinida con España mostrarían que, para ese segmento, apoyar a Cuba constituía aún una suerte de deber, sustentado precisamente en sus experiencias alrededor de un americanismo que consideraban inherente a su país, más allá de que también sus perspectivas solidarias les permitieran cuestionar las políticas del gobierno.

Fue este segmento el que maniobró políticamente para neutralizar la renuncia al americanismo del gobierno y de la mayoría de las élites en ocasión de la visita de Manuel de Quesada, despertando en las élites de provincia y en los sectores medios plebeyos expresiones de solidaridad que mucho más que apelar a los compromisos con Cuba de 1865, pusieron en evidencia que el componente descolonizador del americanismo seguía siendo parte relevante de los sentidos de pertenencia de los chilenos en capacidad de expresarse públicamente. Un americanismo ciudadano se manifestó en Santiago, Valparaíso, Quillota, Rancagua y Concepción, demostrando que más allá de las circunstancias en que algún momento lo habían hecho preeminente, éste seguía vigente en parte de la sociedad.

En la práctica, lo que aconteció entre 1868 y 1875 fue la colisión de un americanismo subyacente en una parte de la sociedad chilena con la opción meditada de la mayoría de las élites y sus gobiernos de concentrarse única y exclusivamente en el país y sus opciones societales, marcando de paso su diferencia con el resto del continente. De esta colisión saldría finalmente vencedora esta última expectativa. Ello estaría determinado por el declinar de la guerra de independencia cubana, pero además por la posición inclaudicable de quienes detentaban realmente el poder político en Chile, de "en nada comprometerse", tal como lo testimonió el último cubano en visitar el país y el único que realmente demandaría directamente del gobierno el apoyo a su causa. Sin duda, otros factores -que escapan a estas reflexionesdeterminaron también que la sociedad patricia chilena optara, a partir de 1865, por concentrarse únicamente en debatir alrededor de la gestión de su país y en marcar la diferencia con los países hispanoamericanos. Como quiera que fuera, a fines de la década del setenta del siglo XIX terminaba 
de manera infructuosa la primera guerra de independencia de Cuba, y Chile iniciaba otra, contra dos de sus aliados cuando el americanismo era la bandera más importante para las élites y su gobierno. Pero entonces ello ya no importaba.

\section{Referencias bibliográficas}

\section{Fuentes primarias}

\section{a. Documentales}

Archivo Histórico Nacional. Fondo Ministerio de Relaciones Exteriores (AHN. FMRE).

\section{b. Impresos}

Chile. Sesiones del Congreso. Cámara de Diputados (1869). Santiago: Biblioteca del Congreso. Sesión 57 extraordinaria en 4 de mayo de 1869.

Chile. Sesiones del Congreso. Cámara de Diputados (1871). Santiago: Biblioteca del Congreso. Sesión 24 ordinaria en 19 de octubre de 1871.

Vicuña Mackenna, B. (1867). Diez meses de misión a los Estados Unidos de Norte América como Ajente Confidencial de Chile, 2 volúmenes, Santiago: Imprenta de La Libertad.

Matta, M. A. (1872). Documentos para un capítulo de la historia diplomática de Chile en su última guerra con España. Santiago: Imprenta del Ferrocarril.

\section{c. Periódicos}

El Ferrocarril, 1865. El Ferrocarril. Santiago, 30 de octubre de 1865. Suplemento al Ferrocarril n. 3068.

El Ferrocarril, 1868. El Ferrocarril, Santiago, 13 de octubre de 1868.

El Ferrocarril, 1869a. El Ferrocarril, Santiago, 16 de mayo de 1869.

El Ferrocarril, 1869b. El Ferrocarril, Santiago, 18 de mayo de 1869.

El Ferrocarril, 1869c. El Ferrocarril, Santiago, 2 de junio de 1869.

El Ferrocarril, 1872. El Ferrocarril, Santiago, 12 de octubre de 1872.

El Ferrocarril, 1872a. El Ferrocarril, Santiago, 10 de octubre de 1872.

El Ferrocarril, 1874. El Ferrocarril, Santiago, 23 de agosto de 1874.

El Ferrocarril, 1874a. El Ferrocarril, Santiago, 25 de agosto de 1874. 
El Ferrocarril, 1874b. El Ferrocarril, Santiago, 27 de agosto de 1874.

El Ferrocarril, 1874c. El Ferrocarril, Santiago, $1^{\circ}$ de septiembre de 1874.

El Ferrocarril, 1874d. El Ferrocarril, Santiago, 8 de septiembre de 1874.

El Ferrocarril, 1875. El Ferrocarril, Santiago, 7 de marzo de 1875.

El Independiente, 1869. El Independiente, Santiago, $1^{\circ}$ de mayo de 1869.

El Independiente, 1869a. El Independiente, Santiago, 7 de mayo de 1869.

El Independiente, 1872. El Independiente, Santiago, 10 de octubre de 1872.

El Independiente, 1874. El Independiente, Santiago, 28 de agosto de 1874.

El Mercurio, 1869. El Mercurio, Valparaíso, 7 de mayo de 1869.

El Mercurio, 1872. El Mercurio, Valparaíso, 8 de octubre de 1872.

El Mercurio, 1874. El Mercurio, Valparaíso, 24 de agosto de 1874.

El Mercurio, 1874a. El Mercurio, Valparaíso, 26 de agosto de 1874.

El Mercurio, 1874b. El Mercurio, Valparaíso, 2 de septiembre de 1874.

El Mercurio, 1874c. El Mercurio, Valparaíso, 7 de septiembre de 1874.

El Mercurio, 1874d. El Mercurio, Valparaíso, 11 de septiembre de 1874.

El Mercurio, 1874e. El Mercurio, Valparaíso, $1^{\circ}$ de octubre de 1874.

La República, 1869. La República, Santiago, 8 de mayo de 1869.

La República, 1869a. La República, Santiago, 9 de mayo de 1869.

La República, 1872. La República, Santiago, 9 de octubre de 1872

El Correo de Quillota, 1874. El Correo de Quillota, Quillota, 6 de septiembre de 1874.

El Correo de Quillota, 1874a. El Correo de Quillota, Quillota, 10 y 13 de septiembre de 1874.

El Correo de Quillota, 1874b. El Correo de Quillota, Quillota, 27 de septiembre de 1874.

El Fénix, 1874. El Fénix, Rancagua, 23 de septiembre de 1874.

El Fénix, 1874a. El Fénix, Rancagua, 29 de septiembre y 6 de octubre de 1874.

La Democracia, 1874. La Democracia, Concepción, 3 de octubre de 1874.

La Revista del Sur, 1874. La Revista del Sur, Concepción, 3 y 8 de octubre de 1874. 


\section{Fuentes secundarias}

Araya, J. (1967). Eugenio María de Hostos en Chile, Chillán: Instituto Profesional de Chillán.

Barrios, R. (2007). Chile en la independencia de Cuba, La Habana: Casa Editorial Verde Olivo.

Barros, M. (1970). Historia diplomática de Chile. 1541-1938. Santiago: Editorial Andrés Bello.

Basadre, J. (1949). Historia de la República del Perú. 2 Tomos, Lima: Editorial Cultura Antártica S. A.

Gazmuri, C. (1992). El "48" chileno. Igualitarios, reformistas, radicales, masones y bomberos. Santiago: Editorial Universitaria.

López, R. (2011). El americanismo en Chile ante la expansión política y militar europea sobre Hispanoamérica (1861-1871). Tesis para optar al grado de Doctor en Estudios Latinoamericanos, Santiago: Facultad de Filosofía y Humanidades, Universidad de Chile. http://repositorio.uchile.cl/tesis/uchile/2011/fi-lopez_r/html/ index-frames.html

Márquez, M. (1967). La diplomacia en nuestra historia, La Habana: Instituto del Libro.

Orrego, E. (1951). Vicuña Mackenna y la Independencia de Cuba: trabajo leído por el Dr. Eugenio Orrego Vicuña en sesión pública, el día 14 de junio de 1951. La Habana: Imprenta el Siglo XX.

Piñeyro, E. (1980). Prosas. La Habana: Editorial Letras Cubanas.

Roa, R. (1970). Aventuras, venturas y desventuras de un mambi en la lucha por la independencia de Cuba. México: Siglo Veintiuno Editores.

Torres-Cuevas, E. y Loyola, O. (2002). Historia de Cuba. 1492-1898. Formación y liberación de la nación. Segunda Edición, La Habana: Editorial Pueblo y Educación.

Zanetti, O. (2013): Historia mínima de Cuba. Madrid: Turner Publicaciones y El Colegio de México. 